\title{
Índios e Africanos no interior paulista: um estudo sobre a transição do cativeiro indígena para a escravidão africana na Vila de Jundiaí, SP, no século XVIII
}

Walter Fagundes Morales*

Flavia Prado Moi**

\begin{abstract}
MORALES, W.F.; MOI, F.P. Índios e Africanos no interior paulista: um estudo sobre a transição do cativeiro indígena para a escravidão africana na Vila de Jundiaí, SP, no século XVIII. Revista do Museu de Arqueologia e Etnologia. São Paulo, 18: 115-131, 2008.
\end{abstract}

Resumo: O objetivo deste artigo é apresentar as análises realizadas a partir das transcrições dos documentos primários "Livro de Óbitos" e "Livro de Casamentos" dos índios e negros ocorridos na "Villa da Nossa Senhora do Desterro de Jundiahy”, SP, Brasil. As informações presentes nessas fontes manuscritas demonstram a significativa presença indígena nesse antigo núcleo de povoamento Paulista até as últimas décadas do século XVIII e o momento em que os segmentos indígenas deixam de ser mão-de-obra cativa e os trabalhos forçados passam a ser cada vez mais atribuídos aos indivíduos de origem e ascendência africana. Os indígenas e seus descendentes passam então à condição de homens livres e ocupantes dos estratos mais baixos da sociedade paulista colonial em formação.

Palavras-chave: Administração Indígena - Brasil Colonial - Escravidão Africana - Jundiaí.

Introdução

s dados apresentados neste artigo foram transcritos, quantificados e analisados a partir de fontes manuscritas inéditas ${ }^{1}$ que

${ }^{*}$ ) Núcleo de Estudos e Pesquisas Arqueológicas da Bahia (NEPAB/UESC).walterfm@terra.com.br $\left.{ }^{(* *}\right)$ Núcleo de Estudos e Pesquisas Ambientais (NEPAM/UNICAMP). flaviapmoi@hotmail.com

(1) Livro de "Óbitos de escravos de Jundiahy", Arquivo do Museu Histórico e Cultural de Jundiaí (MHCJ), e o "Livro de Casamento de escravos", Arquivo da Cúria Diocesana de Jundiaí, SP. demonstram a existência de uma população indigena utilizada como mão-de-obra escrava na vila de Jundiaí, Estado de São Paulo, Brasil, até pelo menos meados do século XVIII.

Os livros de óbitos e casamentos de escravos da "Vila de Nossa Senhora do Desterro de Jundiahy" são documentos onde se registraram todos os óbitos de escravos ocorridos na vila entre os anos de 1744 e 1787 e todos os casamentos realizados entre 1739 e 1777 , respectivamente. Os "escravos" são tanto aqueles de origem indígena que foram capturados nos "sertões" e utilizados como mão-de-obra cativa, como aqueles que vieram para substituí-los, os negros 
Índios e Africanos no interior paulista: um estudo sobre a transição do cativeiro indígena para a escravidão africana na Vila de Jundiaí, SP, no século XVIII.

Revista do Museu de Arqueologia e Etnologia, São Paulo, 18: 115-131, 2008.

trazidos da África. Ao procurar descrever os indivíduos em óbito e as uniões formais perante a Igreja, esses documentos trazem dados sobre as origens, condições sociais e culturais dos agentes envolvidos, e revelam aspectos sobre a inserção, transformação e influência desses segmentos ao longo de grande parte do século XVIII.

É notável que esses dois documentos tragam informações que se complementam e permitiram-nos perceber que em meados da década de 1760 os negros e seus descendentes passam a ocupar o lugar dos indígenas e seus descendentes como mão-de-obra escrava. Os indígenas passam de "administrados" à condição de homens livres ou alforriados, o que representaria o capítulo final do processo de incorporação das etnias indígenas à sociedade colonial paulista. Os africanos, recém-chegados, vêm a se tornar mãode-obra escrava exclusiva no final do século XVIII.

\section{Os indígenas: de livres a escravos}

No dia 9 de junho de 1771 o vigário Ignácio Paes de Oliveira anota no livro de óbitos de escravos de Jundiaí: ${ }^{2}$

“(...) faleceo da vida presente Teresa cayapó, solteyra, escrava, digo administrada, (grifo nosso) de Francisco Moyses e moradora no Japy (...)" (Livro de Óbitos, p. 68 , verso).

O pequeno equívoco rapidamente corrigido de confundir uma administrada, ou seja, uma índia, com uma escrava é sintomático da situação de ambigüidade jurídica e social a que estavam submetidos os povos indígenas durante o Brasil Colonial.

(2) Jundiaí corresponde a um dos núcleos coloniais mais antigos da capitania de São Vicente, com o povoado sendo elevado a vila em 1655 . Seu povoamento ocorreu nas primeiras décadas do século XVII em função da procura por novas terras para o plantio e a necessidade da máxima aproximação da mão-de-obra principal do período: as aldeias indigenas (Petrone 1968; Makino 1981; Monteiro 1994; Campanhole, Santos \& Gicovate 1994; Morales 2000 e 2002).
Nas palavras de Rodolfo Garcia (1956: 131) essa situação refletia:

“(...) uma série ininterrupta de hesitações e contradições, até o ministério do marquês de Pombal, por meados do século XVIII.

Decretava-se hoje o cativeiro sem restrições, amanhã a liberdade absoluta, depois um meio têrmo entre os dois extremos. Promulgava-se, revogava-se, transigia-se, ao sabor dos interesses em voga, e quando enfim se supunham as idéias assentadas por uma vez, recomeçava-se com ardor a teia interminável."

Isso porque, a princípio, perante as leis da Coroa portuguesa os índios eram considerados livres desde que amigos ou aldeados, pois deles partiria a ajuda contra os inimigos e a força para os trabalhos na lavoura e no transporte de mercadorias (Davidoff 1982; Dean 1984). Em contrapartida, deveriam ser pagos e bem tratados, suas aldeias respeitadas e direcionados para o cristianismo. ${ }^{3}$ A escravização somente seria permitida legalmente em caso de guerra justa, quando os índios ameaçassem a segurança dos colonos; resgate, quando os índios fossem salvos por colonos da morte ou cativeiro nas mãos de inimigos (Petrone 1995), ou ainda se impedissem a pregação ou se aliassem aos inimigos da Coroa (Perrone-Moisés 1992).

Entretanto, os colonos necessitavam dos índios para suas lavouras e não concordavam em mantê-los aldeados (Holanda 1990 e 1994). Para suprir suas necessidades de mão-de-obra, tinham que fazer suas próprias expedições de aprisionamento. Desse desencontro de idéias e perspectivas surgiu um longo debate jurídico e moral (Hansen 1998) que ocasionou as constantes mudanças na legislação ${ }^{4}$ seu descompasso

(3) Uma das formas de arregimentar a população indigena eram os descimentos, que correspondiam à transferência voluntária de tribos inteiras e seu assentamento nas proximidades dos povoados coloniais, chamados aldeamentos. Uma vez instalados nos aldeamentos, receberiam proteção dos padres, a fé cristã e principalmente trabalho, já que a mão-deobra indígena era o motor da economia paulista. E era neste ponto que começavam os problemas.

(4) Sobre a legislação indigenista no Brasil consultar PerroneMoisés (1992), Cunha (1992 a e b) e Thomas (1981). 
com a realidade e, não raro, levou ao conflito armado entre colonos e jesuítas (Haubert 1990).

Uma das soluções encontradas para burlar essas leis que impediam a escravização dos indígenas, foi a de evitar a utilização da palavra "escravo" nos documentos e empregar, no que se refere ao trabalho obrigatório dos índios, o termo "administrado", forma encontrada para satisfazer aos colonos e dar "liberdade" aos indígenas (Petrone 1995).

\section{As fontes primárias: forma de abordagem}

As fontes primárias manuscritas, transcritas e analisadas neste artigo - o "Livro de Óbitos"5 e o "Livro de Casamentos" - fazem referência às mortes e aos casamentos da população cativa ${ }^{7}$ durante o século XVIII na vila de Jundiaí, SP. Os registros dos manuscritos são diferentes em sua composição, afinal, tratam de acontecimentos sociais distintos óbitos e casamentos de cativos - mas para os estudos demográficos, são complementares. Ambos fornecem indicações de aspectos do cotidiano dos cativos da vila: status social, origens, redes de parentesco, taxas de mortalidade e condições de saúde, locais de residência e composição dos plantéis (Marcílio 1977; Henry 1977; Morales 2000).

Dentre as informações contidas nesses dois documentos uma das quais mais nos interessa refere-se à procedência dos cativos, pois fornece indícios sobre a origem da população cativa e

(5) Pertencente ao Museu Histórico e Cultural de Jundiaí.

(6) Pertencente ao Arquivo da Cúria Metropolitana de Jundiaí

(7) As pessoas tratadas nestes livros nem sempre são escravas ou administradas. No entanto, no próprio Livro de Óbitos vem anotado "livro de óbitos de escravos”. Assim, apesar de estes livros tratarem também de pessoas com condições jurídicas distintas daquelas diretamente relacionadas ao cativeiro, preferimos manter a denominação original atribuída pelo clero, considerando-a sintomática da condição social das pessoas de origem ou ascendência indígena ou africana na colônia, sempre associada à sua situação de servidão. possibilita diagnosticar a expressão demográfica e o paulatino processo de incorporação das etnias indígenas e africanas à sociedade colonial. Apesar de algumas limitações, como por exemplo, o fato de as classificações existentes nos citados documentos serem quase sempre exógenas, isto é, atribuídas, essas categorias eram claras e funcionais para definir e identificar a situação ao menos aos olhos dos párocos que faziam os registros - dos componentes da colônia.

Nesses registros paroquiais eram os padres que tinham o poder de nomear e classificar a população - como branca, negra ou indígena e, a partir daí, definir sua condição de homens livres, libertos, alforriados, administrados ou escravizados. Entretanto, um africano ou indígena que vivia naquele período sabia muito bem a que grupo social pertencia, mesmo que à sua revelia, porque estava compulsoriamente inserido nele. Só que também se reconheciam enquanto grupo étnico e criavam suas próprias diferenças internas. ${ }^{8}$ Um negro da "nação" Benguela sabia das suas diferenças culturais e lingüísticas com os negros da Guiné, tanto quanto um índio Bororo em relação ao Paresi. E como corroboram os dois documentos, as variações internas entre os chamados "índios" e "negros" era significativa. Apenas na vila de Jundiaí do século XVIII foi possível constatar, a partir do manuscrito "Livro de Óbitos de escravos", pelo menos quatro denominações para os indígenas (Carijó, Kayapó, Paresi e

(8) Como a identidade étnica é uma questão essencialmente política e suas fronteiras podem aparecer, desaparecer ou se modificar, dependendo do momento (Jones 1997), essas associações criavam grupos, os grupos étnicos, que tinham o poder de definir quem está dentro ou fora dele. A autoidentificação dos seus componentes deveria ser compartilhada e aceita também entre os outros grupos, criando categorias relacionais, dicotomizadas (Drummond 1981; Todorov 1988; Novaes 1993). Dessa relação eram construídas as diferenças reais, imaginárias ou até impostas (Brandão 1986; Balibar \& Wallerstein 1988; León 1992) que, independentemente das necessidades, transformações e estratégias adotadas, continuaram atreladas ao passado desses indivíduos por meio de uma série de hábitos, costumes e outros atributos culturais de origem indígena ou africana (Morales 2000). 
Índios e Africanos no interior paulista: um estudo sobre a transição do cativeiro indígena para a escravidão africana na Vila de Jundiaí, SP, no século XVIII.

Revista do Museu de Arqueologia e Etnologia, São Paulo, 18: 115-131, 2008.

Tabela 1

\begin{tabular}{lcccccccc}
\hline \multicolumn{8}{c}{ Porcentagem geral da população registrada no Livro de Óbitos (1744 -1787) } \\
\hline $\begin{array}{l}\text { Condição } \\
\text { Social }\end{array}$ & Adm. & Esc. & Forros & Pardos & Bast. & Lib. & S/R & Total \\
\hline \hline & $11 \%$ & $48 \%$ & $22 \%$ & $2 \%$ & $1 \%$ & $5 \%$ & $11 \%$ & $100 \%$ \\
& $(142)$ & $(612)$ & $(274)$ & $(29)$ & $(11)$ & $(61)$ & $(142)$ & \\
\hline
\end{tabular}

Bororo) e três para os africanos (os da Guiné, do Congo e de Benguela). ${ }^{9}$

\section{O Livro de Óbitos}

As anotações manuscritas existentes neste documento referem-se aos 1.271 óbitos ocorridos entre os anos de 1744 e 1787 e anotados pelos diversos vigários responsáveis pela Igreja da Matriz da Vila de Jundiaí. Em cada um destes registros foi possivel sistematizar os dados, classificando-os em categorias bem definidas. A estrutura do banco de dados foi montada para receber as informações constantes em cada óbito, como a data e o nome do falecido, sua condição social e estado civil, idade, origem étnica, nome do cônjuge (se casado) ou do pai e da mãe quando solteiro, e a respectiva condição social de cada um deles, local de sepultamento e residência, nome do vigário e ocasionais informações sobre a causa da morte ou redes de parentesco. Se o falecido era cativo, constava ainda entre as informações o nome do seu proprietário.

As condições sociais, de origem e jurídicas dos cativos foram agregadas aqui sob o termo "Condição Social" e classificadas em sete categorias básicas, cuja distribuição entre os anos de 1744 e 1787 é a seguinte: escravos (48\%), alforriados (22\%), administrados (11\%), sem referência (11\%), libertos $(5 \%)$, pardos (2\%) e bastardos (1\%) (Tabela 1).

No período global, o somatório dos escravos, alforriados e libertos, que em geral é associado à ascendência africana, parece apontar para uma presença significativa de segmentos dessa origem nos plantéis, sobrando pouco mais de 10\% de indivídu-

(9) Deve-se ainda salientar que as definições eram quase sempre genéricas, na maior parte das vezes não apresentando qualquer informação sobre a origem das pessoas. os indigenas entre os cativos da vila de Jundiaí. Entretanto, uma leitura mais atenta dos registros e preocupada em entender o significado de cada uma dessas categorias, oferece um panorama bem distinto, pois as formas de classificar os indivíduos escravizados sofreram, ao longo do tempo, grandes alterações nos registros documentais.

O termo escravo, por exemplo, contabilizado neste trabalho como indivíduos de ascendência africana durante os anos quinhentos e seiscentos, era empregado nos testamentos, inventários e livros de óbitos ou nascimento para também designar os índios. No inventário de Paula Fernandes, em 1614, esposa falecida de Raphael de Oliveira (que anos mais tarde seria um dos fundadores da vila de Jundiai), temos entre as "gentes de serviços: ${ }^{10}$

\section{"Um nego por nome Andre de nação} tememinó com sua mulher Marina com uma filha da mesma nação por nome Francisca Apolonia teminó casada com um negro por nome Balthazar que esta no sertão com seu senhor com um filho por nome Balthazar e outro Amador".

A utilização dos termos "nego", "escravo" ou "da nação tememinó” eram de uso comum para denominar os índios em épocas que a presença dos africanos era pouco intensa. Somente com o aumento do tráfico negreiro no final do século XVII e os problemas referentes à legislação - que proibia a escravização dos índios - os termos para diferenciar os dois grupos começam a ficar mais claros e definidores da sua procedência (Lopes 1988). Os registros passaram então a designar índios e índias escravizados como "administrados", "escravos da terra" ou, mais comumente, através de uma origem étnica genérica, como "carijó".

(10) Série Inventários e Testamentos. Vol. 2, Departamento do Arquivo do Estado de São Paulo, 1953. 


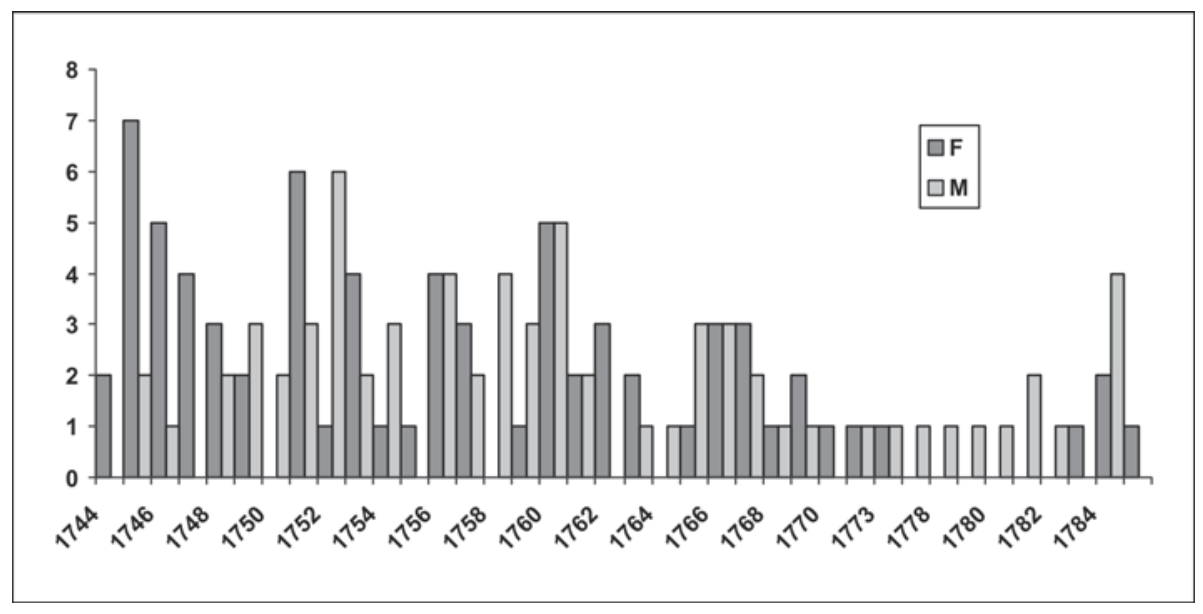

Gráfico 1. Distribuição masculino/feminino entre os administrados.

Os africanos eram, então, designados simplesmente como escravos, expressão que lhes era exclusiva no Livro de Óbitos, ou como "da nação banguela", "do gentio da Guiné”, “do Congo" - estas últimas qualificações encontradas nos registros documentais que muitas vezes fazem referência ao porto de saída na costa africana (Ramos 1934 e 1943) - ou, simplesmente, escravos. ${ }^{11}$

O emprego da palavra "administrado" é o que apresenta menores dúvidas quanto ao seu significado. Ela corresponde a indivíduos de origem indígena que, não podendo ser escravos, eram registrados como "administrados" na documentação. A condição social dos administrados representa apenas $11 \%$ do total de mortos entre os anos de 1744 e 1788, ou seja, um período de pouco mais de 40 anos. Quando contabilizado a cada 11 anos, esse mesmo período oferecerá um outro quadro demográfico. De 1744 a 1754, temos o período em que aparece a maior densidade de indígenas anotados como administrados $-27 \%$ do total dos cativos registrados no Livro de Óbitos. No período seguinte, de 55 a 65 , tem início um

(11) Há nove referências à origem africana no Livro de Óbitos: "Benguela" (5), "Congo" (3) e "Guiné" (1). Os africanos trazidos para a região de São Paulo no final do século XVIII e início do XIX eram, em sua grande maioria, Banto de "Angola", saídos sobretudo dos portos de Luanda e Benguela (Slenes 1991-1992). lento, porém constante declínio populacional, que resulta em $18 \%$ do total de falecimentos, até atingir 5\% entre 1766 e 1776, e 3\% entre 1777 e 1787 (Gráfico 1).

Pelo exposto, constata-se a presença de indígenas capturados nos sertões e trazidos para trabalhar na vila de Jundiaí até pelo menos meados do século XVIII. ${ }^{12}$ Antes dessa data seu número devia ser ainda maior, como atestam as fontes cartoriais de cidade próximas como São Paulo em período anterior (Tabela 2).

A mesma certeza com que se traduzem os termos "administrado" e "escravo" como sinônimos de indígenas e africanos não existe entre as categorias "sem referência", "liberto" e "alforriado". Em "sem referência", como o próprio nome diz, estão os óbitos sobre os quais não existem informações que indiquem a condição social do falecido. Os falecidos incluídos nessa categoria normalmente possuem

(12) Temos 28 referências à origem indigena no Livro de Óbitos: "carijo" (21), "caiapo" (5), "Bororó” (1), e "Parecy" (1). Os chamados Carijó, termo amplo que englobava uma série de grupos falantes de línguas Tupi-Guarani, eram os cativos preferenciais dos colonos paulistas desde os primeiros tempos do século XVII (Schaden 1954). Da mesma forma, os Kayapó trazidos para a vila de Jundiaí não representam um grupo específico e sim um termo geral para os falantes da família lingüística Jê. Estes grupos ocupavam uma vasta região que vai do noroeste de São Paulo até o norte de Goiás (Turner 1992). 
Índios e Africanos no interior paulista: um estudo sobre a transição do cativeiro indígena para a escravidão africana na Vila de Jundiaí, SP, no século XVIII.

Revista do Museu de Arqueologia e Etnologia, São Paulo, 18: 115-131, 2008.

Tabela 2

"Proprietários e índios, região de São Paulo,
1600-1729, segundo os inventários de bens"
(Monteiro 1994: 80)

\begin{tabular}{lrrr}
\hline Década & Proprietários & Índios & Posse Média \\
\hline $1600-9$ & 12 & 154 & 12,8 \\
$1610-9$ & 49 & 863 & 17,6 \\
$1620-9$ & 38 & 852 & 22,4 \\
$1630-9$ & 99 & 2804 & 28,3 \\
$1640-9$ & 111 & 4060 & 36,6 \\
$1650-9$ & 142 & 5375 & 37,9 \\
$1660-9$ & 148 & 3752 & 25,3 \\
$1670-9$ & 138 & 3686 & 26,7 \\
$1680-9$ & 159 & 3623 & 22,8 \\
$1690-9$ & 71 & 1058 & 14,9 \\
$1700-9$ & 63 & 948 & 15,0 \\
$1710-9$ & 100 & 927 & 9,3 \\
$1720-9$ & 40 & 435 & 9,9 \\
$1600-1729$ & 1174 & 28537 & 24,3 \\
\hline
\end{tabular}

sobrenome (o que não ocorre com os escravos ou administrados), indicando terem uma condição social diferenciada, possivelmente libertos ou alforriados, mas não é possível identificar se sua origem é indígena ou africana. ${ }^{13}$

Já os libertos, principalmente os alforriados, ${ }^{14}$ são categorias-chave para o entendimento do processo de assimilação de indígenas à sociedade colonial, pois contêm não só africanos, mas também ex-administrados, isto é, índios que passaram a uma nova condição social, como comprova o registro de óbito de 6 de outubro de 1771:

“(...) faleceo da vida presente Patrício, forro, solteyro, Borórô, com os sacramentos da penitencia e extrema unçam de idade de

(13) Os manuscritos revelam que conviviam na Jundiaí colonial, por exemplo, os "crioulos", "mulatos" (geralmente filhos de branco e negra), africanos recém-chegados e que ainda falavam apenas sua língua nativa ("boçais"), "ladinos", que eram os escravos trazidos há mais tempo, "cayapó vindo do sertão" (Livro de Óbitos 28\04\1767) e índios aldeados, existindo o registro de falecimento de índios aldeados, incluindo alguns de Barueri e São Miguel.

(14) Stuart Schwartz (1995:451) define em seu glossário o termo forro como "(1) escravo liberto; (2) indio legalmente livre, mas sob controle português". noventa annos pouco mais ou menos esta sepultado no adro desta igreja, matriz de Jundiahy e fregues dessa freguesia e morador no bairro do Jacarê" (Livro de Óbitos, p. 70, verso).

Ou o de 11 de janeiro de 1784, quando:

“(...) faleceo da vida presente Ignacio, liberto, solteiro, filho de Antonio Gonsalves, e de sua mulher Gertrudes de Brito, carijos forros, moradores no bairro do rio abaixo(...)" (Livro de Óbitos, p. 120).

Os dois casos indicam que indígenas estão entre os alforriados. Poder-se-ia supor que, nos casos da alforria de administrados, registrar-se-ia sempre a origem, como nos exemplos acima "carijós forros" e "forro Borórô". Um dos indicadores de que isso não acontece (ou, ao menos, não acontece em todos os casos), pode ser percebido quando relacionamos a distribuição dos alforriados e administrados simultaneamente (ver Gráfico 2).

Podemos perceber um sensivel declínio populacional dos administrados a partir da metade da década de 1760, exatamente na mesma época em que os alforriados passam a ser mais assíduos nos registros. Esse quadro permite supor estarmos diante de uma situação de mudança na forma de anotação dos administrados na documentação cartorial, que seria o capítulo final do processo de incorporação dos indígenas à sociedade colonial paulista. Acreditamos que os registros de óbitos demonstrem o momento da passagem definitiva dos indivíduos de ascendência indígena para a condição de homens livres, com a configuração dos africanos como mão-de-obra escrava exclusiva.

É claro que esse processo de incorporação dos indígenas à sociedade colonial ocorre desde a chegada dos primeiros portugueses às terras brasileiras, que ao se relacionarem com as índias, tinham filhos com elas - os chamados mamelucos paulistas -, cujos hábitos e características culturais eram marcadamente indígenas (Ribeiro 1995: 106-113). A miscigenação branco/índio foi tão grande e a intensidade demográfica de tal monta que vários autores afirmam que até meados do século XVIII existia a utilização 


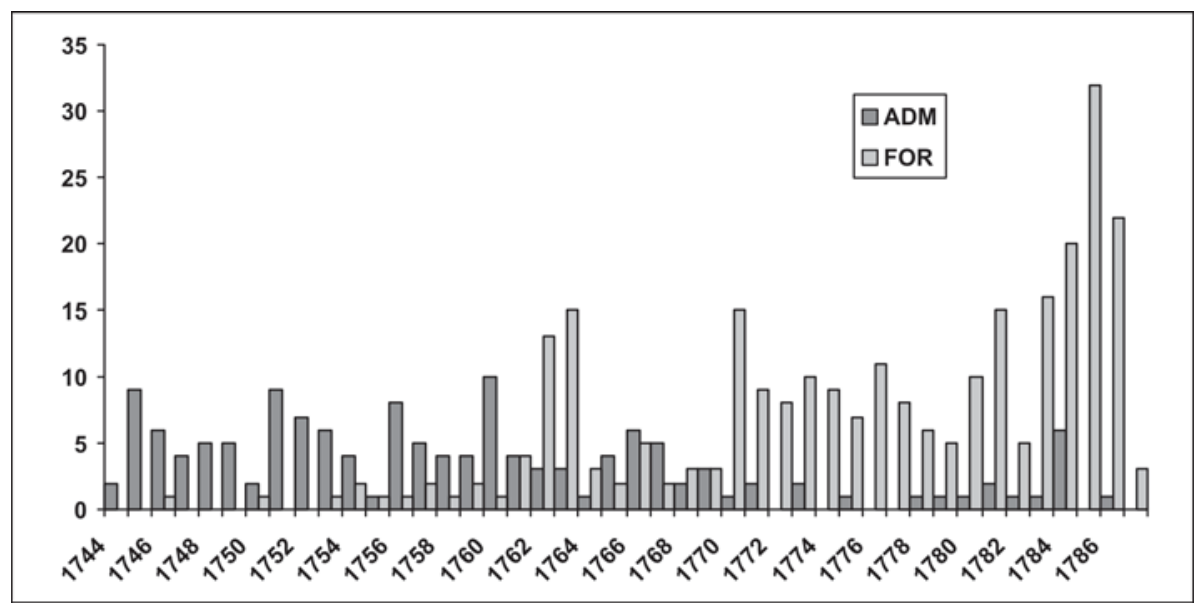

Gráfico 2. Proporção entre administrados e alforriados.

corrente de uma língua geral $^{15}$ nas áreas rurais da capitania de São Paulo (Holanda 1995: 123-133).

Darcy Ribeiro traçou o resultado final dessa situação:

\section{"O brasilindio como o afro-brasileiro} existiam numa terra de ninguém, etnicamente falando, e é a partir dessa carência essencial, para livrar-se da ninguendade de não-índios, não-europeus e não-negros, que eles se vêem forçados a criar a sua própria identidade étnica: a brasileira" (Ribeiro 1995: 131).

Essa "brasilidade", no entanto, estava longe de se concretizar durante o transcorrer do século XVIII. A inserção dos africanos e índios na sociedade colonial se processava de maneira bastante desigual. ${ }^{16}$
Os bastardos e os pardos eram produto direto da incorporação de indígenas e africanos à sociedade colonial. No contexto analisado ambos os termos são utilizados para os descendentes de índios e portugueses. Os pardos ${ }^{17} \mathrm{e}$ bastardos, que somados contribuem com apenas $3 \%$ de todos os registros, têm uma súbita ascensão nos anos em que ocorre a diminuição dos administrados e o aumento dos alforriados, entre 1763 e 1769 (Gráfico 3).

Esse fato, longe de ser uma coincidência, traz novos elementos para explicar a diminuição dos administrados nos registros a partir das décadas de 1770 e 1780 . Os indígenas e seus descendentes não desapareceram simplesmente, mas passam a ser vistos e registrados de outra forma. Não são
(15) Esta língua correspondia a uma espécie de dialeto Tupi que, misturado a elementos do português, servia como idioma base para o entendimento entre as diversas etnias indigenas e os luso-brasileiros. A progressiva diminuição na demografia indígena, pouco a pouco, fez recuar a influência da língua geral, dando origem ao modo de falar caipira (Petrone 1995). Sobre os usos e formas de apropriação da língua geral desde o século XVII até seu uso atual pelos Baré do rio Negro, ver o artigo de Barros, Borges e Meira (1996). (16) Essa diversidade apontada pelas fontes escritas é também confirmada nos vestígios retirados em escavações arqueológicas realizadas em antigas sesmarias da região. Segundo Morales (2001), os atributos da cerâmica encontrada nesses assentamentos estão atrelados a uma identidade cultural vinculada aos grupos portadores de cerâmica conhecida arqueologicamente como Tupiguarani. Além disso, existem evidências de que vários dos motivos decorativos estão relacionados aos segmentos trazidos da África, já que remetem a padrões utilizados naquele continente, ou porque aparecem em sítios arqueológicos do sul do Brasil em época que coincide com a chegada de escravos africanos à região (Jacobus 1996), e não apresentam nenhuma semelhança com a cerâmica pré-colonial brasileira.

(17) Para Petrone (1995: 370), os pardos englobam em São Paulo basicamente a população mestiça de brancos com índios, apesar de possuírem uma pequena participação de negros. Já em outras regiões, como a do Rio de Janeiro durante o século XVIII, o termo "pardos" correspondia exclusivamente à terceira geração de africanos (Faria 1998: 307). 
Índios e Africanos no interior paulista: um estudo sobre a transição do cativeiro indígena para a escravidão africana na Vila de Jundiaí, SP, no século XVIII.

Revista do Museu de Arqueologia e Etnologia, São Paulo, 18: 115-131, 2008.

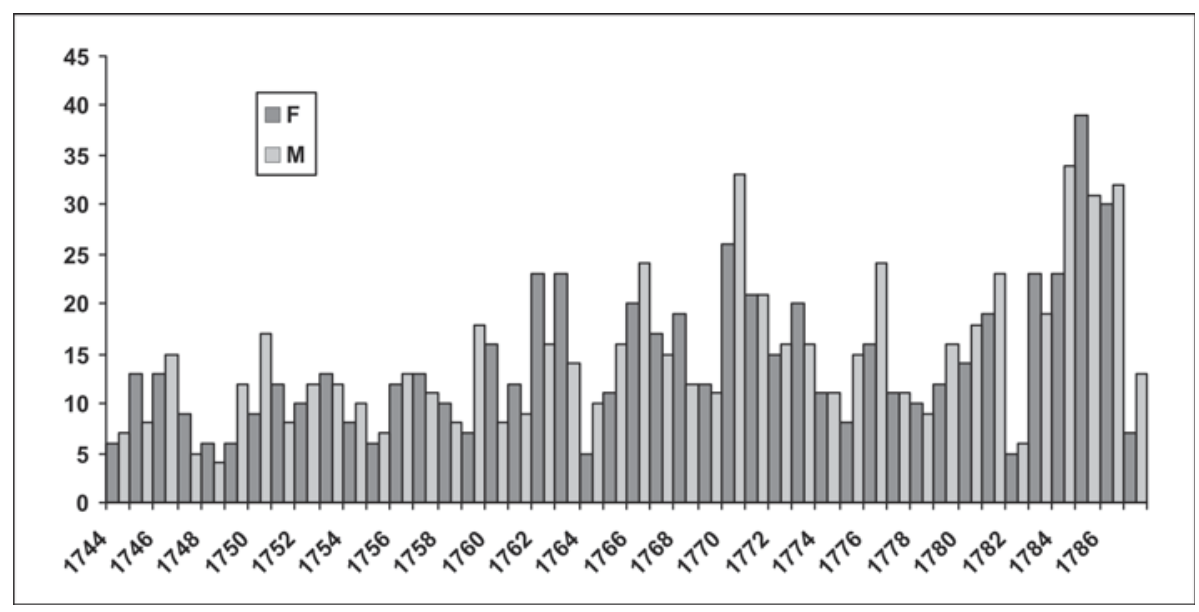

Gráfico 3. Proporção geral entre administrados, bastardos e pardos.

mais tratados como "índios", "administrados", "gentio" ou "negro da terra", pois a semelhança dos traços resultantes da carga genética, ocasionada por 250 anos de miscigenação, tornava cada vez mais difícil distinguir, visualmente, quem era ou não indígena na sociedade paulista (Ribeiro 1996). O mesmo não acontecia com o negro africano. Seus traços fenotípicos nos lábios, cabelos e da cor da pele o distinguiam de imediato da população branca e mameluca. A dificuldade na identificação racial dos habitantes de São Paulo pode ser sentida na anotação do vigário Joseph Rodrigues Bueno em 24 de janeiro de 1768, dia em que:

“(...) faleceo da presente vida Miguel q. não sey se bastardo, ou branco, e nem me souberam informar os conductores filho de quem era; pessoa muito pobre, q por isso fiz pello amor de Deos, a que a mi me pertencia, fregues dessa freguesia e morador no citio do Sarg. Mor Antonio de Moraes (...)" (Livro de Óbitos, p. 49, verso).

Neste pequeno trecho podemos perceber a situação que afligiu o vigário. Mesmo estando diante do morto para encomendar sua alma, não conseguia, a partir da observação do cadáver, definir sua condição social - se bastardo ou branco. Este fragmento de texto testemunha uma situação que começa a se configurar a partir de meados dos setecentos de maneira definitiva: a passagem dos indivíduos de ascen- dência indígena, quer sejam eles administrados, pardos ou bastardos, para a condição de homens livres, libertos ou alforriados, ocupantes dos estratos sociais mais baixos da sociedade.

Na condição de homens livres, a ascendência indígena já não caracterizava por si só o indivíduo, porque grande parte da população paulista a possuía em alguma medida. As características físicas que influenciavam este julgamento não podiam ser determinantes. Uma vez incorporadas aos estratos livres da sociedade colonial, mesmo que sua condição jurídica ainda as determinasse administradas, essas pessoas deixariam de ser vistas exclusivamente por suas características físicas. A distinção passou cada vez mais a estar relacionada à situação econômica/ social.

Com a passagem definitiva dos segmentos indígenas a uma nova condição social, os africanos assumem o papel do escravo "padrão" na expansão econômica que começava a tomar forma com o início do ciclo da cana-de-açúcar. ${ }^{18}$

A freguesia de Campinas, devido à proximidade com Jundiaí, é um bom parâmetro das

(18) Nas terras paulistas, a importação africana em larga escala aconteceu apenas a partir das derradeiras décadas do século XVIII, período em que a cana-deaçúcar, e logo em seguida o café, alavancaram a economia paulista definitivamente (Queiroz 1967, Marcílio 1974, Linhares \& Silva 1981). 
transformações econômicas e de composição dos plantéis que o açúcar acarretou na região. Inicialmente termo de Jundiaí e distante $40 \mathrm{~km}$ dela, Campinas possuía as mesmas características econômicas, isto é, uma agricultura de subsistência e - de acordo com Slenes (1998) - tinha apenas 156 cativos em 1779. Esse quadro alterou-se rapidamente com a produção de açúcar em larga escala. Campinas foi elevada à vila em $1797^{19}$ e passou a importar escravos africanos em grande número, atingindo a cifra de 4.800 em 1829, número superior à população livre da vila (Slenes 1998:18). As novas levas de escravos africanos trazidas para a região no início do século XIX fizeram com que os escravizados passassem a ter um número de homens bem superior ao de mulheres, como em outras partes da colônia (Schwarcz 1996).

Observando o recenseamento de 1797 da Capitania de São Paulo (Tabela 3), percebe-se que havia nas vilas paulistas um número maior de mulheres entre os pardos e os brancos e uma pequena vantagem numérica masculina entre os negros. $^{20}$

Tabela 3

\begin{tabular}{|c|c|c|c|c|}
\hline \multicolumn{5}{|c|}{$\begin{array}{l}\text { "Mappa geral dos habitantes da Capitania de } \\
\text { S. Paulo no anno de } 1797 \text { " } 11\end{array}$} \\
\hline & Totaes & Brancos & Pretos & Pardos \\
\hline Homens & 77.175 & 42.270 & 20.669 & 14.236 \\
\hline Mulheres & 81.275 & 47.053 & 17.971 & 16.251 \\
\hline Sommas & 158.450 & 89.323 & 38.640 & 30.487 \\
\hline
\end{tabular}

Na Jundiaí dos setecentos, a soma de todos os falecidos, independentemente da idade ou condição social, oferece um surpreendente equilíbrio entre os sexos - $51 \%$ são homens e

(19) Sobre a elevação de Campinas a vila ver D.I (Diversos), vol. 3, pp.3-14, 1913.

(20) Na província de São Vicente a dependência do tráfico negreiro, que privilegiava a vinda de homens, somente ganhou maior importância depois da segunda metade do século XVIII.

(21) D.I, Vol 31, 1901. A tabela aqui apresentada é um resumo do recenseamento. O original nos oferece também a divisão entre os sexos com as respectivas faixas etárias.
49\% mulheres, ou seja, uma razão de masculinidade praticamente igual ${ }^{22}$ (Gráfico 4).

Contudo, excluindo os inocentes e os recémnascidos da contabilidade, ou seja, enfocando apenas os adultos (acima dos 14/15 anos), a desproporção entre os sexos começa a aparecer em determinadas condições sociais. Os bastardos são os que apresentam a menor razão de masculinidade 71 (ou seja, para cada 100 mulheres na população são 71 homens), seguido pelos sem referência e alforriados com proporções um pouco maiores (82), os libertos com 90, e os administrados com 94, mantendo, assim, uma predominância feminina nestas categorias (Tabela 4).

Somente estão fora desta tendência os escravos africanos, com a razão de 126 (para cada 100 mulheres há 126 homens), e os pardos, com 170. No caso dos escravos africanos trata-se da confirmação de uma situação observada largamente em outras regiões da colônia _ o alto custo determinava a preferência, na hora da compra, pela escolha da mão-de-obra masculina à feminina (Paiva 1995) (Gráfico 5).

Essa situação de equilíbrio entre os sexos em várias das categorias sociais e em certa medida até entre os negros, propiciou um crescimento vegetativo da população cativa, fato pouco comum em regiões que dependiam diretamente da importação de escravos africanos para manterem sua demografia constante (Silva 1984; Ferreira 2006 e 2007).

No caso das uniões entre os indígenas e os "brancos" haveria até um interesse da coroa em integrar esses segmentos à sociedade, como se pode perceber pelo alvará de 4 de abril de 1775 , no qual o rei de Portugal declara:

"Eu El-Rei, sou servido declarar que os meus vassalos deste reino e da América que casarem com as indias dela não ficam com infâmia alguma, antes se farão dignos de real atenção. Outrossim proíbo que os ditos meus vassalos casados com indias ou seus descendentes, sejam tratados com o nome de caboclos ou outro semelhante que possa ser

(22) A razão de masculinidade é definida realizando a divisão do total de homens pelo de mulheres e multiplicando o produto por 100 . 
Índios e Africanos no interior paulista: um estudo sobre a transição do cativeiro indígena para a escravidão africana na Vila de Jundiaí, SP, no século XVIII.

Revista do Museu de Arqueologia e Etnologia, São Paulo, 18: 115-131, 2008.

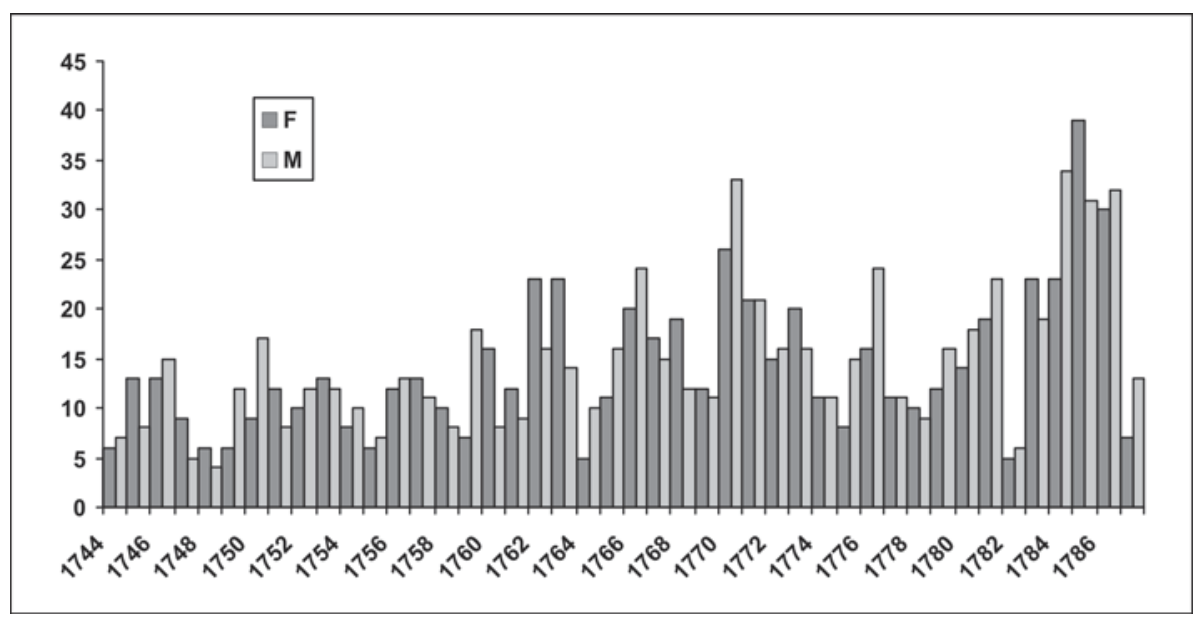

Gráfico 4. Total de cativos (homens e mulheres).

Tabela 4

\begin{tabular}{cccccccc}
\hline \multicolumn{6}{c}{ Razão da masculinidade* } & entre os cativos adultos ${ }^{* *}$ na Vila de Jundiaí (1744-1787) \\
\hline & Administrados & Escravos & Alforriados & Bastardos & Pardos & Libertos & Sem Referência \\
\hline $\mathrm{R} \mathrm{M}^{*}$ & 94 & 126 & 82 & 71 & 170 & 90 & 81
\end{tabular}

* Razão de masculinidade (divisão do número de homens pelo de mulheres e multiplicado por cem).

** Acima dos 14 anos.

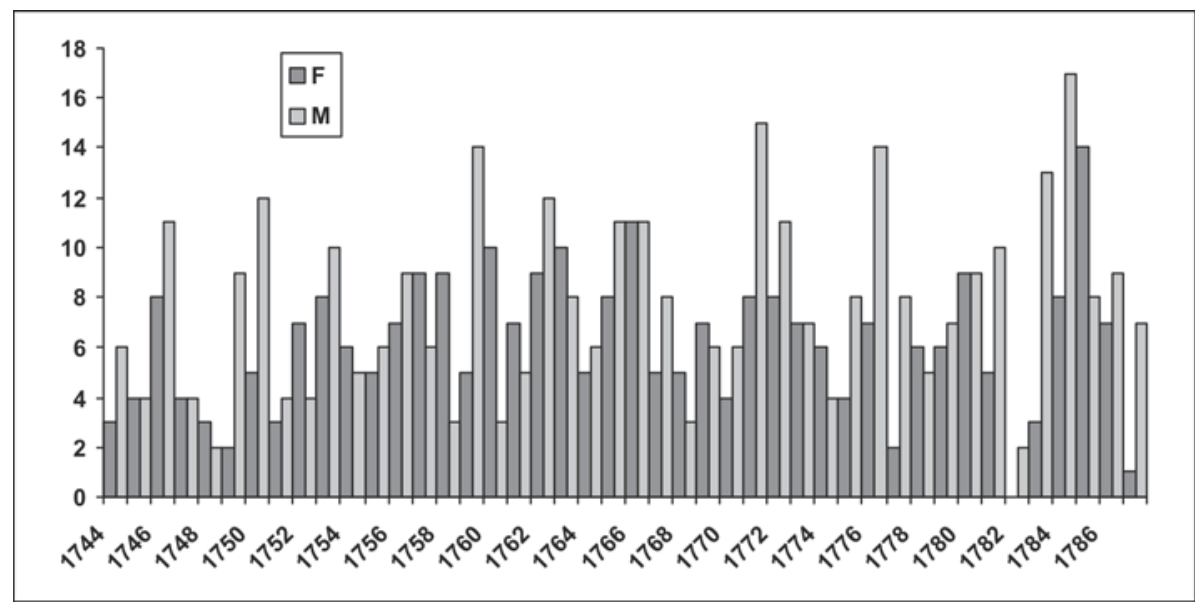

Gráfico 5. Proporção masculino/feminino entre os escravos de origem africana.

injurioso. O mesmo se praticará com portuguesas que se casarem com indios" (Souza Filho 1994:158).

A análise da Tabela 5 apresenta a razão de masculinidade geral dividida por períodos entre os administrados, escravos e alforriados. Pode-se perceber melhor a existência de um equilíbrio na razão de masculinidade entre os cativos, havendo inclusive, em alguns anos, um número de mulheres ligeiramente superior ao dos homens.

Durante a análise do documento "Livro de Óbitos” também foi possivel detectar registros indicativos dos anos de vida que as pessoas tinham 
Tabela 5

\begin{tabular}{lccccc}
\hline \multicolumn{5}{c}{ Razão da taxa de masculinidade entre os cativos da Vila de Jundiaí (Livro de Óbitos de Jundiaí) } \\
\hline & RM - Geral & Administrados & Escravos & Alforriados & Sem Referência \\
\hline $1744 / 1754$ & 105 & 68 & 134 & 50 & 133 \\
$1755 / 1765$ & 90 & 113 & 100 & 61 & 100 \\
$1766 / 1776$ & 104 & 83 & 129 & 100 & 77 \\
$1777 / 1778$ & 110 & 250 & 156 & 82 & 80 \\
\hline
\end{tabular}

ao falecer, classificados nesse banco de dados como "faixa etária". Para esta categoria, criada pelo vigário da igreja matriz de Jundiaí para classificar, sem muito rigor, a idade do morto, temos as seguintes faixas temporais: "velho", "inocente", "recém-nascido" e "sem referência". Em muitos registros a classificação por faixa etária está acompanhada da idade numérica. A partir destas anotações pode-se chegar à conclusão de que os "inocentes" correspondem às crianças de até 12 anos, e os "sem referência" aos adultos (dos 14 até os 50/60 anos). Quanto à faixa etária "velhos", refere-se aos cativos com mais de 60/65 anos. De uma maneira geral, as anotações sobre a idade das crianças, ou inocentes, como eram chamadas na época, têm um maior cuidado com a exatidão. Os adultos são sempre aproximações e os registros das pessoas mais idosas exagerados na longevidade, atingindo muitas vezes mais de 100 anos. ${ }^{23}$

Observando-se a quantidade de "velhos" existentes entre as categorias, é possível obter mais elementos para confirmar a existência de uma maior quantidade de mulheres alforriadas do que de homens. Para tanto, contabilizamos quantos foram classificados como "velhos" ao morrer e chegamos a $8 \%$ de homens e $5 \%$ de mulheres (Gráfico 6).

A resposta a essa aparente contradição está entre os alforriados. Nesta categoria 16\% dos "velhos" são mulheres, contra 13\% dos homens.

(23) Para uma breve discussão sobre a classificação etária na documentação cartorial ver Schwartz (1995: 288).

\section{Gráfico 6}

Total de cativos distribuídos pela idade (17441787)

\begin{tabular}{ccccc}
\hline $\begin{array}{c}\text { Faixa } \\
\text { etária }\end{array}$ & Adultos & Velhos & Inocentes & $\begin{array}{c}\text { Recém- } \\
\text { nascidos }\end{array}$ \\
\hline \hline & $49 \%$ & $9 \%$ & $33 \%$ & $9 \%$ \\
$(630)$ & $(110)$ & $(420)$ & $(111)$ \\
\hline
\end{tabular}

Obs.: Os adultos, diferentemente das outras três categorias, não estão discriminados como tal no Livro de Óbitos, onde encontramos apenas a idade do morto, que corresponde dos 14 aos 50/60 anos.

Confirma-se que as mulheres, além de terem uma expectativa de vida maior, recebem a alforria com mais freqüência, como podemos perceber no Gráfico 7.

Como última informação sobre o manuscrito de óbitos tem-se a residência dos cativos falecidos (Tabela 6). Em 663 dos 1271 registros anotou-se o local de residência e, destes, 479 são de falecimentos ocorridos em bairros de Jundiaí ou localidades próximas. As 184 residências restantes, não anotadas na tabela, referem-se a vilas distantes, na maior parte dos casos em outras províncias, como Minas Gerais, Rio de Janeiro ou Goiás.

\section{O Livro de Casamentos}

O manuscrito "Livro de casamentos de escravos de Jundiai" teve seus 204 registros de casamentos efetuados entre os anos de $1739 \mathrm{e}$ 1777. Os gráficos 8 e 9 apresentam as condições sociais dos cônjuges.

Os registros de casamento permitem analisar as alianças entre os cativos, bem como comparar suas informações com aquelas provenientes dos óbitos, validando a representatividade da amostra e diminuindo as omissões senhoriais dos registros. 


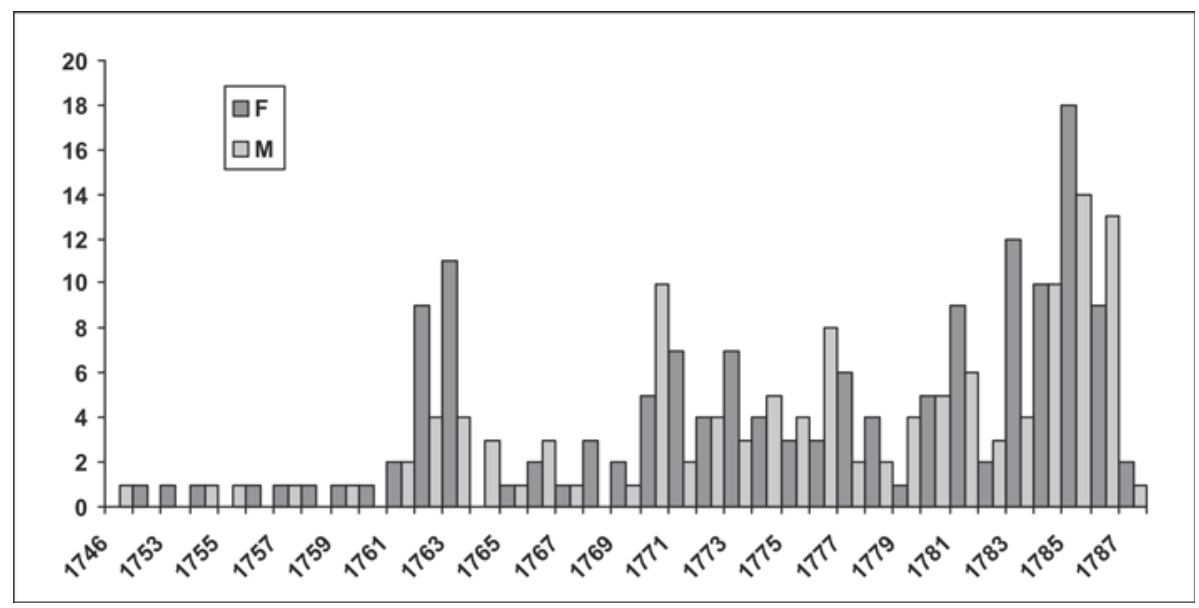

Gráfico 7. Total de alforriados separados por sexo.

Tabela 6

\begin{tabular}{lc}
\hline \multicolumn{2}{c}{ Local de residência dos falecidos } \\
\hline \multicolumn{1}{c}{ Locais } & $\begin{array}{c}\text { Número } \\
\text { de Citações }\end{array}$ \\
\hline \hline Japi & 80 \\
Rio-Abaixo & 71 \\
Bairro do Capivari & 80 \\
Jundiaí-Mirim & 41 \\
Rio das Pedras & 42 \\
Olaria & 6 \\
Vila & 35 \\
Cachoeirinha & 15 \\
Jacaré & 6 \\
Rocinha & 4 \\
Cururu & 4 \\
Bairro do Mato Grosso & 12 \\
Rio Acima & 1 \\
Bairro do Moises & 2 \\
Itupeva & 31 \\
Vila de N.S de Atibaia & 3 \\
Capela & 1 \\
Bairro do Ubucu & 1 \\
Caminho de Goiases & 4 \\
Mato Dentro (no caminho de Goiases) & 4 \\
Vila das Lages & 1 \\
Juqueri & 1 \\
Santana do Parnaíba & 2 \\
Capão & 32 \\
Total de registros & 479 \\
\hline
\end{tabular}

A análise e comparação das informações retiradas de ambos os livros oferecem números bastante semelhantes entre si no que se refere às condições sociais dos cativos (Tabelas 7 e 8).

A comparação entre os dois bancos de dados apresenta semelhanças de proporcionalidade entre os escravos e administrados. A única variação significativa acontece na categoria dos alforriados, bem menos expressiva no livro de casamentos, talvez em decorrência de haverem sido anotados em outro livro ou viverem em concubinato.

Sobre a família escrava, os casamentos e a escolha do cônjuge, foi possível perceber que era muito mais fácil ocorrer enlaces de escravos africanos com índias do que índios administrados com escravas africanas.

Os enfoques dos trabalhos relacionados à estrutura familiar no Brasil têm sofrido grandes alterações nos últimos anos, tornando-se cada vez mais clara a percepção da inexistência de um só tipo de organização familiar entre a população escrava. As variações são consideráveis em função das características de origem, de condição social e de tempo e espaço. As pesquisas mais recentes, amparadas em dados da demografia histórica, ${ }^{24}$ buscam revelar aspectos mais

(24) Como trabalho de referência podemos citar a publicação "População e Família" do Centro de Estudos de Demografia Histórica da América Latina (CEDAHAL/USP), 1998. 
Tabela 7

\begin{tabular}{ccccccccc}
\hline \multicolumn{8}{c}{ Cativos registrados no livro de Casamentos e suas respectivas condições sociais $(1739-1777)$} \\
\hline \multicolumn{1}{c}{ Adm. } & Esc. & Forros & Pardos & Bast. & Lib. & S/R & Total \\
\hline$\%$ & 18,1 & 49,5 & 5,1 & 2,2 & 5,8 & 2,4 & 16,6 & 100 \\
ABS & 74 & 202 & 21 & 9 & 24 & 10 & 68 & 408 \\
\hline
\end{tabular}

Tabela 8

\begin{tabular}{cccccccrr}
\hline \multicolumn{8}{c}{ Cativos registrados no livro de Óbitos e suas respectivas condições sociais $(1744$-1787) } \\
\hline \multicolumn{1}{c}{ Adm. } & Esc. & Forros & Pardos & Bast. & Lib. & S/R & Total \\
\hline$\%$ & 11 & 48 & 22 & 2 & 1 & 5 & 11 & 100 \\
ABS & 142 & 612 & 274 & 29 & 11 & 61 & 142 & 1271 \\
\hline
\end{tabular}

cotidianos e domésticos da vida familiar dos escravos, preocupados principalmente em demonstrar a possibilidade de os escravos formarem famílias extensas e nucleares ao longo de várias gerações (Mattos 1998; Martins 1996; Florentino \& Góes 1997 e Slenes 1987). Neste contexto, a estrutura familiar escrava deixa de ser vista como um elemento passivo das vontades e desmandos dos seus senhores, com uma organização familiar ausente ou caótica onde os relacionamentos sexuais eram marcados pela promiscuidade.

É certo que a vontade de formar uma família, por meio do casamento ou da união informal, esbarrava em limitações de várias ordens. A principal delas era a situação de servidão em que estavam inseridos e cujo representante imediato era o seu senhor (Mattoso 1990).

O casamento entre os cativos era visto pelos senhores como algo que poderia trazer uma série de problemas, pois os escravos eram um bem e a formação de uma família acarretaria sérios conflitos e tensões se houvesse a necessidade de desmembramento em decorrência da venda ou partilha de um dos seus membros. Além disso, sempre havia a possibilidade de problema quanto ao local de residência do casal caso os escravos fossem de donos distintos. Em função disso, e para atenuar esses conflitos, o casamento entre cativos do mesmo proprietário era quase uma regra a ser seguida (Faria 1998: 314 e Schwartz 1995: 313-319).

Na vila de Jundiaí também foi possível perceber a interferência dos senhores na hora do casamento. Dos 204 casamentos registrados, em apenas $4,9 \%$ os cônjuges eram de proprietários distintos e em 33,8\% eram do mesmo proprietário. Em 28,9\% dos casos, está anotado apenas o proprietário de um dos cônjuges. Dentre os demais casais, $32,4 \%$ eram de indivíduos alforriados, libertos, pardos ou sem referência quanto à condição social (Tabela 9).

As maiores proporções de cônjuges do mesmo proprietário podem ser encontradas entre casamentos em que ambos os parceiros são de origem ou ascendência africana $(74,4 \%)$, contra apenas 2,9\% de proprietários diferentes.

A Tabela 10 demonstra em maior detalhe os casamentos registrados na vila de Jundiaí e as respectivas condições sociais dos cônjuges. É possivel perceber diferenças significativas na hora da escolha (ou imposição) dos parceiros e várias

Tabela 9

\begin{tabular}{lcccc}
\hline \multicolumn{5}{c}{ Distribuição total dos proprietários dos cônjuges } \\
\hline $\begin{array}{c}\text { Mesmo } \\
\text { Proprietário }\end{array}$ & $\begin{array}{c}\text { Proprietários } \\
\text { Diferentes }\end{array}$ & $\begin{array}{c}\text { Sem Anotação } \\
\text { do Proprietário }\end{array}$ & $\begin{array}{c}\text { Apenas um } \\
\text { Proprietário }\end{array}$ \\
\hline Porcentagem & $33,8 \%$ & $4,9 \%$ & $28,9 \%$ & $32,4 \%$ \\
Quantidade & 69 & 10 & 66 & 59 \\
\hline
\end{tabular}


Índios e Africanos no interior paulista: um estudo sobre a transição do cativeiro indígena para a escravidão africana na Vila de Jundiaí, SP, no século XVIII.

Revista do Museu de Arqueologia e Etnologia, São Paulo, 18: 115-131, 2008.

uniões interétnicas. Temos um número ligeiramente maior de administradas casando com elementos de origem africana $(9,3 \%)$ do que com os de sua própria origem $(8,3 \%)$. Entretanto, o inverso não ocorre: apenas $2 \%$ de administrados casam com mulheres escravas. Essas proporções devem estar relacionadas à menor disponibilidade de mulheres entre os africanos, que compensam esta ausência casando com as administradas. No que se refere aos casamentos entre escravos e escravas, eles somam a maioria dos casos, sendo $38,5 \%$ do total.

\section{Considerações finais}

Os dados sintetizados neste artigo demonstram a existência de uma população indígena utilizada como mão-de-obra escrava na vila de Jundiaí até pelo menos meados do século XVIII. Além disso, contribui na busca das origens dos agentes envolvidos ao reunir elementos sobre aspectos da inserção, transformação e influência desses segmentos até as últimas décadas do século XVIII.

Para atingir esses resultados foram transcritas, quantificadas e analisadas fontes manuscritas inéditas - os livros de "Óbitos" e de "Casamentos" de escravos - para auxiliar na compreensão da demografia da população cativa da região. Essas fontes revelaram informações sobre a composição étnica dos plantéis cativos originári- os dos "sertões" e da África na região de Jundiaí durante o período colonial, os casamentos entre grupos de procedências distintas e, principalmente, as transformações que os indígenas sofreram desde sua captura nos sertões para utilização como mão-de-obra cativa, até seu paulatino processo de incorporação à sociedade colonial como pessoas livres ou alforriadas.

Outro dado significativo para aqueles interessados em entender a inserção indígena na sociedade colonial foi a percepção sobre o modo de caracterizar a situação de mudança na forma de anotar os índios cativos - ou administrados na documentação cartorial do período. Essa mudança seria o capítulo final do processo de incorporação das etnias indígenas à sociedade colonial paulista. Acreditamos que os registros de óbitos e, em menor medida os de casamentos, demonstram o momento e a forma como se deu a passagem definitiva dos indivíduos de ascendência indígena para a condição de homens livres no final do século XVIII e a configuração dos africanos como a mão-de-obra escrava exclusiva. Por fim, esses documentos primários atestam e quantificam que os trabalhos forçados passam a ser cada vez mais atribuídos aos indivíduos de origem e ascendência africana e que os indígenas e seus descendentes, fossem eles administrados, pardos ou bastardos, na condição de homens livres e alforriados, passaram a ocupar os estratos sociais mais baixos e menos abastados da sociedade paulista.

Tabela 10

\begin{tabular}{lcccccccc}
\hline \multicolumn{7}{c}{ Condição social dos cativos e do(a) parceiro(a) } \\
\hline & Adm. & Esc. & Forros & Pardos & Bast. & Lib. & S/R & Total \\
\hline Adm. & $8,3 \%$ & $9,3 \%$ & $2 \%$ & $0,5 \%$ & $0 \%$ & $1 \%$ & $0 \%$ & $21,1 \%$ \\
Esc. & $2 \%$ & $38,5 \%$ & $2,5 \%$ & $0 \%$ & $0 \%$ & $1,5 \%$ & $1 \%$ & $45,5 \%$ \\
Forros & $1 \%$ & $1,5 \%$ & $1 \%$ & $0 \%$ & $0 \%$ & $0 \%$ & $0,5 \%$ & $4 \%$ \\
Pardo & $0 \%$ & $1,5 \%$ & $0 \%$ & $0,5 \%$ & $0 \%$ & $0 \%$ & $1 \%$ & $3 \%$ \\
Bast. & $0,5 \%$ & $0 \%$ & $0 \%$ & $0 \%$ & $1,5 \%$ & $0 \%$ & $0,5 \%$ & $2,5 \%$ \\
Lib. & $0 \%$ & $1,5 \%$ & $1 \%$ & $0,5 \%$ & $0 \%$ & $3 \%$ & $0,5 \%$ & $6,5 \%$ \\
S/R & $3,4 \%$ & $1 \%$ & $0 \%$ & $0 \%$ & $1 \%$ & $0 \%$ & $12 \%$ & $17,4 \%$ \\
Total & $15,2 \%$ & $53,3 \%$ & $6,5 \%$ & $1,5 \%$ & $2,5 \%$ & $5,5 \%$ & $15,5 \%$ & $100 \%$ \\
\hline
\end{tabular}


MORALES, W.F.; MOI, F.P. Amerindians and Africans in the São Paulo state interior: a study of the transition from bondage of indigenous persons to African slavery in the Vila de Jundiai settlement, São Paulo, in the $18^{\text {th }}$ century. Revista do Museu de Arqueologia e Etnologia. São Paulo, 18: 115-131, 2008.

\begin{abstract}
The aim of this article is the presentation of analyses made from the primary sources "Book of Deaths" and "Book of Marriages" of Amerindians and Africans in the settlement "Villa da Nossa Senhora do Desterro de Jundiahy", São Paulo, Brazil. The information presented in these manuscripts demonstrates the significant presence of Amerindians in this center of settlement in the São Paulo state interior until the last decades of the $18^{\text {th }}$ century. It demonstrates the moment in which the indigenous segments of the population first stop being bonded labor and forced labor becomes increasingly attributed to individuals of African origin and descendance. At that same time indigenous people and their descendants transitioned to the condition of free men and came to occupy the lowest strata of the forming 'paulista' colonial society.
\end{abstract}

Keywords: African slavery - Indian slavery - Colonial Brazil - Jundiaí.

\title{
Referências bibliográficas
}

\section{Fontes primárias}

\section{Documentos Manuscritos}

- "Livro de Óbitos de escravos de Jundiahy", Arquivo do Museu Histórico e Cultural de Jundiaí, SP.

- "Livro de casamentos de escravos", Arquivo da Cúria Diocesana de Jundiaí, SP.

\section{Documentos publicados}

- Documentos Interessantes para a História e Costumes de São Paulo, Departamento do Arquivo do Estado de São Paulo.

- Repertório das Sesmarias concedidas pelos capitães Generais da Capitania de São Paulo desde 1721 até 1821, Departamento do Arquivo do Estado, 1944.

\section{II - Fontes secundárias}

\section{BALIBAR, E.; WALLERSTEIN, I.}

1988 Race, nation, classe, les identités ambigües. Paris: La decouverte.
BARROS, M.C.; BORGES, L. C.; MEIRA, M. 1996 A Língua Geral como identidade construída. Revista de Antropologia, 39 (1): 191- 219.

BRANDÃO, C.R.

1986 Identidade e etnia: construção da pessoa e resistência cultural. São Paulo: Brasiliense.

CAMPANHOLE, A.; SANTOS, W; GICOVATE, M. 1994 Aditamentos à história da fundação de Jundiaí. São Paulo: Litarte.

CUNHA, M.C.

1992a Política indigenista no séc. XIX. In: Cunha, M.C. (Org.) História dos índios no Brasil. São Paulo, FAPESP/SMC/ Companhia das Letras: 133-154.

CUNHA, M.C. (Org.)

1992b Legislação indigenista no século XIX: uma compilação: 1808-1889. Colaboração de Mara Manzoni Luz, Beatriz Perrone-Moisés. São Paulo: Ed. da Universidade de São Paulo, Comissão Pró-Índio de São Paulo.

DAVIDOFF, C.H.

1982 Bandeirismo: verso e reverso. Coleção tudo é história (47). São Paulo: Brasiliense.

DEAN, W.

1984 The Indigenous populations of the São Paulo-Rio de Janeiro coast: trade, 
Índios e Africanos no interior paulista: um estudo sobre a transição do cativeiro indígena para a escravidão africana na Vila de Jundiaí, SP, no século XVIII.

Revista do Museu de Arqueologia e Etnologia, São Paulo, 18: 115-131, 2008.

aldeamento, slavery and extinction. Revista de história, 117: 3-26.

DRUMMOND, L.

1981 Ethnicity, 'ethnicity' and culture theory. Man, 16 (4): 693-696.

FARIA, S.C.

1998 A colônia em movimento: fortuna e família no cotidiano colonial. Rio de Janeiro: Nova Fronteira.

FERREIRA, R.G.

2007 A Amizade e a alforria: um trânsito entre a escravidão e a liberdade (Porto Feliz, SP, século XIX). Afro-Asia (UFBA), 35: 83-141.

2006 Sociedade Escravista e Mudança de Cor. Porto Feliz, São Paulo, Século XIX. In: Fragoso, J.; Florentino, M.; Jucá, A.C.; Campos, A. (Orgs.) Nas Rotas de Império. Vitória / Lisboa: EDUFES / IICTP, 1: 447-488.

FLORENTINO, M.; GÓES, J.R.

1997 A paz das senzalas: famílias escravas e tráfico atlântico, Rio de Janeiro, c. 1790 - c.1850.

GARCIA, R.R. Rio de Janeiro: Civilização Brasileira.

1956 Ensaio sobre a história politica e administrativa do Brasil. Col. Documentos Brasileiros. Rio de Janeiro: José Olympio Editora.

HANSEN, A.J.

1998 A servidão natural do selvagem e a guerra justa contra o bárbaro. In: Novaes, A. (Org.) A descoberta do homem e do mundo. São Paulo, Companhia das Letras: $347-373$.

HAUBERT, M.

1990 Índios e jesuitas no tempo das missões. São Paulo: Companhia das Letras, Círculo do Livro.

HENRY, L.

1977 Técnicas de análise em demografia histórica. Curitiba: Universidade Federal do Paraná. HOLANDA, S.B.

1990 Monções. (3ª. Ed.), Ampliada. São Paulo: Brasiliense.

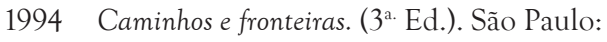
Companhia das Letras.

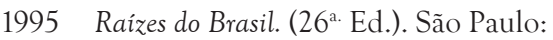
Companhia das Letras.

JACOBUS, A.L.

1996 Resgate arqueológico e histórico do Registro de Viamão (Guarda Velha, Santo Antônio da Patrulha/RS). Dissertação apresentada ao curso de pós-graduação em história do IFCH da Pontifícia Universidade Católica do Rio Grande do Sul, Taquara.
JONES, S.

1997 The Archaeology of Ethinicity: constructing identities in the past and present. London and New York: Routledge.

LEÓN, L.V.

1992 Ser indio otra vez: la purepechización de los Tarascos serranos. Cidade do México: Consejo nacional para la cultura y las artes.

LINHARES, M.; SILVA, F.C.T.

1981 História da agricultura brasileira: combates e controvérsias. São Paulo: Brasiliense.

LOPES, N.

1988 Bantos, Malês e identidade negra. Rio de Janeiro: Forense Universitária.

MAKINO, M.

1981 Jundiaí: povoamento e desenvolvimento, 1655-1854. Dissertação de Mestrado apresentada à Faculdade de Filosofia, Letras e Ciências Humanas da Universidade de São Paulo (FFLCH/USP), São Paulo.

MARCÍLIO, M.L.

1974 Crescimento demográfico e evolução agrária paulista - 1700/1836. Tese apresentada ao concurso para Livre Docência em História Contemporânea, Faculdade de Filosofia, Letras e Ciências Humanas da Universidade de São Paulo (FFLCH/ USP), São Paulo.

1977 Demografia histórica. São Paulo: Pioneira. MARTINS, V.

1996 Nem senhores, nem escravos: os pequenos agricultores em Campinas; 1800-1850. Coleção Campiniana, 10. Campinas: CMU/UNICAMP.

MATTOS, H.M.

1998 Das cores do silêncio: os significados da liberdade no Sudeste escravista, Brasil século XIX. Rio de Janeiro: Nova Fronteira.

MATTOSO, K.M.

1990 Ser escravo no Brasil (3ª. ed.). São Paulo: Brasiliense.

MONTEIRO, J.M.

1994 Negros da terra: indios e bandeirantes nas origens de São Paulo. São Paulo: Companhia das Letras.

MORALES, W.F.

2000 A escravidão esquecida: a administração indígena em Jundiai durante o século XVIII. Dissertação de Mestrado apresentada ao Programa Interdepartamental da Faculdade de Filosofia, Letras e Ciências Humanas (FFLCH), Museu de Arqueolo- 
gia e Etnologia da Universidade de São Paulo (MAE-USP), São Paulo.

2001 A cerâmica "neo-brasileira" nas Terras Paulistas: um estudo sobre as possibilidades de identificação cultural através dos vestígios materiais na Vila de Jundiaí do século XVIII. Revista do Museu de Arqueologia e Etnologia, 11: 165-187.

2002 Índios e Africanos na Jundiai Colonial. Jundiaí: Secretaria de Planejamento e Meio ambiente.

NOVAES, S.C.

1993 Jogo de espelhos: imagens da representação de si através dos outros. São Paulo: Editora da Universidade de São Paulo/USP.

PAIVA, E.F.

1995 Escravos e libertos nas Minas Gerais do século XVIII: estratégias de resistência através dos testamentos. São Paulo: Annablume (Selo universidade: 43).

PERRONE-MOISÉS, B.

1992 Índios livres e índios escravos: os princípios da legislação indigenista do período colonial (séculos XVI a XVIII). In: Cunha M.C. (Org.) História dos indios no Brasil. São Paulo, Fapesp/SMC/ Companhia das Letras: 115-132.

PETRONE, M.T.S.

1968 A lavoura canavieria em São Paulo: expansão e declínio; 1765-1851. São Paulo: Difusão Européia do Livro.

PETRONE, P.

1995 Aldeamentos Paulistas. São Paulo: Edusp.

QUEIROZ, S.R.

1967 Algumas notas sobre a lavoura de açúcar em São Paulo no período colonial. Anais do Museu Paulista/USP, 21: 109-277.

RAMOS, A.

1934 O negro brasileiro. Brasília: Livraria Brasiliense.

1943 Introdução à antropologia brasileira. Coleção Estudos Brasileiros, 1.

RIBEIRO, D.

1995 O povo brasileiro: a formação e o sentido do Brasil. São Paulo: Companhia das Letras.

1996 Sobre a mestiçagem no Brasil. In: Schwarcz, L.M.; Queiroz, R.S. (Orgs.) Raça e Diversidade. São Paulo, Edusp, Estação Ciência: 187- 211.
SCHADEN, E.

1954 Os primitivos habitantes do território paulista. Revista de história, 8 (18): 385-406.

\section{SCHWARCZ, L.M}

1996 Ser peça, ser coisa: definições e especificidades da escravidão no Brasil. In: Schwarcz, L.M.; Reis, L.V.S. (Orgs.) Negras imagens: ensaios sobre cultura e escravidão no Brasil. São Paulo, Edusp: 11-29.

SCHWARTZ, S.B.

1995 Segredos Internos: engenhos e escravos na sociedade colonial, 1550-1835. São Paulo: Companhia das Letras.

SILVA, M.B.N.

1984 Sistema de casamento no Brasil colonial. São Paulo: Editora da Universidade de São Paulo.

SLENES, R.W.

1987 Escravidão e família: padrões de casamento e estabilidade familiar numa comunidade escrava (Campinas, Século XIX). Revista de Estudos Econômicos, IPE/USP, 17 (2): 212-217.

1991-1992 Malungu, ngoma vem: África coberta e descoberta no Brasil. Revista USP - Dossiê Quinhentos anos de América, 12: 48-67.

1998 A formação da família escrava nas regiões de grande lavoura do Sudeste: Campinas, um caso paradigmático no século XIX. CEDHAL/USP/ Humanitas População e família, 1 (1): 9-82.

SOUZA FILHO, C.F.M.

1994 O direito envergonhado: o direito e os índios no Brasil. In: Grupioni, B. L. (Org.) Índios do Brasil. Brasília: Ministério da Educação e do Desporto.

THOMAS, G.

1981 Política indigenista dos portugueses no Brasil (1500-1640). São Paulo: Loyola.

\section{TODOROV, T.}

1988 A conquista da América: a questão do outro. São Paulo: Editora Martins Fontes.

TURNER, T.

1992 Os Mebengokre Kayapó: história e mudança social. De comunidades autônomas para a coexistência interétnica. In: Cunha M.C. (Org.) História dos indios no Brasil. São Paulo, Fapesp/SMC/ Companhia das Letras: 311-338. 